nicht erklïren kann. Vielleicht werien sie einst auf die Geheimnisse der Organisation einiges Licht werfen.

Venn man den Gang der Natur bei der Bildung der ver. schiedenen Substanzen, welche die Elemente der organisirten Wesen bilden, untersucht, so erkennt man bald, dass die meisten ihren Ursprung gewissen neutralen Subsianzen verdanken, wie z. B. dem Eiweiss, Fibrin, dem Blute, welches in ganzen lebenden Körper vertheilt ist, und dem Stärkmehl, welches in den meisten Samenkörnern dem Embryo zur Nahrung dient und ihn quf Kosten seiner Substanz entwicklt; man sieht also, dass die lebende Natur sich durch cinc Folge von successiven Umbildungen erhält und unaufhörlich erneuert; und dass, wäbrend im Mineralreiche alles unbeweglich ist und nur durch Zufall variirt, das Pfanzen - und Thierreich in steter Bewegung eine unendliche Reihe von Metamorphosen zeigen.

Kehren wir zu der Ursache und zu clen Umständen der Solidification der Oele zurück und beobachten den langsamen und successiven Gang, solle man da nicht eine merk würdige Aehnlichkeit zwischen dieser Modification der Substanz and denen erkennen, welche unaufhörlich im Iunern der Organisation ror sich gehen?

\title{
Ueber Salicin aus den Blättern von Salix Helix W.;
}

von

Fr. Nees von Esenbeck in Buns.

Der atisnehmend bittere Geschmack, welchen die Bläller von Salix Helix $W$. und $S$. purpurea $W$. besitzen, veranlasste Annal. d. Pharm. IV Bds. 1 IIft. 
mich, einen meiner Zuhörer, Herm Becker, einen geechick. ten Plarmaceuteli, aufzufordern, diese Blälter unler meiner teitung auf iluren Gehalt un Salicin zu prüfen. Es wurden zu diesem Zwecke dic Bliiter von Snlix Helix, die airh von Srolix purpiurea blos durch itiren baumartigen Wuchs und ihre bedeutende Grösse so wie durch die blusse gelbliche Farbe dee jungen Zweige unterscheidet, im Juni gesaumelt und an der Sonne gel rocknet. Von diesen getrockneten Blältern wurden 15 Unzen zweimal mit heissem Gummi auggezogen und die erhalfene sehr billere Flïssigkeit zur Extractconsistcnz verdunstet. Das Extract wurcie hierauf in Weingeist von go p.C. gelïst, wobei sich eine bedeuteule Menge eines braunen, den in den Rinden enthalienen ähnlich, ausschied. Die geitige Lisurg: konte durch Bebandeln mit Koble nicht entfïrbt werden, wir wir dies friber anch bei der Bereitung des Sulicins aus der Rinde ron Salix witellina bewerkt hollen., Nach Entfernung des Weingeistez reagirte die Fhissigkeit sauer, zeigle aber durch den Versach mit thierischen Lein die Abwesenheil des Gerbestoffes. Uin die freie säurs zn entfernen, setzlen wir elwaz Kalkailch zu und bemerkten dabei plöılich eine auffallende Erscheinung; der angnelme $W$ reidengeruci war verschwunden and an seine blelle ein slarker hörhat widriger Geruch getreten. Es erinnert dies an die flüchtigen Alkalcite der narkotischen Pfanzen, die gewiss als P'rodukte des clezinischen P'rocesses zu belrachten seyz mügen *).

Da die Minsigheit jetal noch hunkler gefärbt war, so blieb vichı ibrig, als sie min hasisch - essigsauresn Blei zu behatijeln, wodurch sie nach starker fallung blos weingelb gefärbt ersthiezi. Zungleich trat jetzt der Weidengeruch wieder

*) Näratich wemn sie hierbei zerlegt und altentalls noch mit audicrn aurch dio Operation himugukommewen Stofien rer. unreinigt werden, sonst nicht.

G. 
mehr herver, und wurde nach dem Behandeli der Flüssigkeil mit Schwefelwasseratoff und dem darauf rorgenommenen Verdunsten wieder ganz hergestellt, woraus man echliessen könute, dass der durch den Kalk neu entstandene übsle Geruch nicht nus drm Aroma der Weidenhlätler, sondern aus den andern Stoffen derselben durch cise Zerseszung und neue Combination entstanden beyn müchte. (Bei einen Versuch auf flüchtige Pflanzenalkaloide würen also niclit gerade stark riechende Ptanzen nōihig) *). Un die freie Essigsäure zu entfernen und das Verdunsten lexselben zu befödern, saturirIen wir die Fiüssigkeit mil: Ammoniak, wodurch aber eino auffallende dunkle Färbung und ein Ausscheiden eines braunen Stoffes einiral. Zur starken Syrupsconsistenz abgerauch, erstarrte das Ganze zu einer braunen krystalinischen Masse, die durcb Abwaschen eine nicht unbedeutende Menge reints Salicin lieferte. Die Abwaschtlussigheit war zebr bitter, sio konnte aber auch durch thierische Kohle nicht entfürbl werden und gah nach dem Verdunsten norh einanal eiwas Salicin, so dass die gonze Quastitü an 2 Drachmen belrag.

Ich lege eine kleine Probe bei * ).

†) Allerdings ist es viciat nöthig, dass die darsuf zu untersuchenden Planzentheile Geruch haben, denn die reifen Früchte von Conium mecularum sind ganz gerucinios und enthalten am ineisten Coisiin.

G.

**) Das von dem Herrn Verfasser giitigst erhaltene Salicin int ein weisses, aus höclist zarten Krystallchen besteherdes Pulver von sehr bitterus Geschmeck des Salicins. Eine Probe devon verlirantit hirterliess kaum einen Hauch Asche.

S. 